\title{
Constraints on the origins of Pacific FOZO domains from ${ }^{142} \mathrm{Nd}$ compositions
}

BRADLEY PETERS ${ }^{1}$ AND PATERNO R CASTILLO ${ }^{2}$

\author{
${ }^{1}$ ETH Zürich
}

${ }^{2}$ University of California, San Diego

Presenting Author: bradley.peters@erdw.ethz.ch

Although the mantle geochemical 'focus zone' (FOZO) is the sole link between isotopically depleted and enriched endmember domains sampled by volcanic hotspots, the origins of FOZO itself have remained elusive. In part, this is a consequence of the fact that FOZO is neither a singular composition nor directly comparable to geological materials sampled at Earth's surface. As a result, FOZO-type hotspot components have been variably described as representatives of primordial, BSE-like material unaffected by recycling or as bulk recycled materials, including relatively young components, possessing muted isotopic characteristics compared to isotopically enriched endmember domains.

For example, the $\mathrm{Pb}$ and $\mathrm{Os}$ isotopic compositions of the FOZO-type Réunion hotspot have generally been regarded as evidence of a relatively unprocessed mantle source preserved for at least $2 \mathrm{Ga}$. Such a conclusion is supported by Hadean-aged ( $>4 \mathrm{Ga})$ isotopic heterogeneity in the ${ }^{146} \mathrm{Sm}{ }^{142} \mathrm{Nd}$ system $\left(\mathrm{t}_{1 / 2}=\right.$ $103 \mathrm{Ma}$ ) for Réunion basalts. We similarly apply ${ }^{142} \mathrm{Nd}$ isotopic compositions as a test for ancient components in two Pacific hotspots with strong FOZO components: the Juan Fernandez hotspot and the Marquesas hotspot. In order to maximize the potential for detecting Hadean-aged heterogeneity, our analyses provide precisions of $3.7 \mathrm{ppm}$ for the terrestrial standard $(2 \sigma$ s.d. of all standards) and $2.0 \mathrm{ppm}$ for BHVO-2 (precision-weighted $95 \%$ c.i., $n=8$ ).

Both hotspots show a relatively restricted range of $\mu^{142} \mathrm{Nd}$ (ppm composition relative to the terrestrial standard), with Marquesas basalts showing a slightly elevated range $\left(\mu^{142} \mathrm{Nd}=\right.$ $+7.0 \pm 1.7$, precision-weighted $2 \sigma$ s.d., $n=5$ ) compared to Juan Fernandez basalts $(+3.6 \pm 2.1, n=6)$. The maximum $\mu^{142} \mathrm{Nd}$ compositions measured for Marquesas basalts are similar to those of Réunion and imply that Hadean components may be preserved in some FOZO hotspots. However, the generally lower $\mu^{142} \mathrm{Nd}$ signature observed in Juan Fernandez basalts illustrates that FOZO-type mantle domains may in some cases represent relatively young material. Taken together, these data reinforce the idea that FOZO is not singular, and that many distinct FOZO domains may exist in the modern mantle. Alternatively, they may illustrate that the minor Hadean component observed in hotspots exists outside FOZO in a yet-uncharacterized mantle reservoir. 